\section{AB0518 - JUVENILE SYSTEMIC LUPUS ERYTHEMATOSUS RELATED PANCREATITIS: AN UNCOMMON MANIFESTATION OF A COMMON DISEASE}

Anjani Gummadi, Ankita Singh, Rakesh Kumar, Johnson Nameirakpam, Pandiarajan Vignesh, Deepti Suri, Anju Gupta, Ankur Jindal, Amit Rawat, Surjit Singh. Post Graduate Institute of Medical Education and Research, Chandigarh, Pediatrics, Advanced Pediatric centre, Chandigarh, India

Background: Pancreatitis is a rare but potentially life-threatening complication of juvenile systemic lupus erythematosus (jSLE).

Objectives: We report 3 children with SLE who presented with acute pancreatitis.

Methods: We have reviewed the clinical records of 140 children with SLE between period of 1993-2018. Three of them present with acute pancreatitis.

Results: Case 1-12-year-girl presented with fever of 1 month and alopecia. Examination revealed pedal oedema, periorbital puffiness, generalised lymphadenopathy, large joint arthritis and mild hepatomegaly.Investigations were consistent with lupus.Renal biopsy revealed Class 3 lupus nephritis and initiated on intravenous methylprednisolone.Two days after beginning her medication,she developed severe epigastric pain and vomiting which did not respond to antacids and analgesic.Serum amylase and lipase were elevated.Clinical possibilities included steroid induced pancreatitis and lupus pancreatitis. Intravenous methylprednisolone was continued following which she showed a dramatic improvement.Case 2-A-6-year-old presented with pain abdomen and vomiting. Physical examination showed epigastric tenderness.Investigations showed elevated amylase levels.Computerised tomography(CT) abdomen revealed acute necrotising pancreatitis. A ultrasound abdomen revealed a pancreatic pseudocyst. He had a second episode of acute pancreatitis along with anasarca after 3 months.In follow-up,he presented with anasarca. Investigation were consistent with lupus.Following the initiation of steroids, he improved and there has been no recurrence of pancreatitis over the next 4 years.Case 3- 9-year-girl presented with generalised rash and alopecia for 5 months. She also had pain abdomen for last 2 months. Investigations showed elevated amylase and ultrasound abdomen revealed acute pancreatitis. She had undergone a laparotomy elsewhere.Examination showed generalised pigmented rash, periorbital edema, alopecia, periorbital puffiness, hard palate ulcer and surgical scar on the abdomen. Urinalysis showed nephrotic range proteinuria.Serum amylase levels were elevated. Ultrasound abdomen revealed a pancreatic pseudocyst.Further investigations were suggestive of lupus. Workup for APLA revealed positive lupus anticoagulant. She was initiated on oral prednisolone and was given pulses of intravenous cyclophosphamide.There has been no recurrence of pancreatitis over 12-years followup.

\begin{tabular}{|c|c|c|c|}
\hline Investigation & Case 1 & Case 2 & Case 3 \\
\hline Haemoglobin (g/L) & 92g/L & $96 \mathrm{~g} / \mathrm{L}$ & $80 \mathrm{~g} / \mathrm{L}$ \\
\hline White cell counts & $7.7 \times$ & $7.8 \times 10^{6} / \mathrm{L}$ & $7.5 X$ \\
\hline Lymphocyte count & $\begin{array}{l}10^{6} / \mathrm{L} \\
2.15 \mathrm{x} \\
10^{6} / \mathrm{L}\end{array}$ & $1.9 \times 10^{6} / \mathrm{L}$ & $\begin{array}{c}10^{6} / \mathrm{L} \\
1.95 \times 10^{6} \\
\mathrm{~L}\end{array}$ \\
\hline Platelets & $\begin{array}{c}130 \times 10^{9} \\
\mathrm{~L}\end{array}$ & $150 \times 10^{9} / \mathrm{L}$ & $\begin{array}{l}420 x \\
10^{9} / L\end{array}$ \\
\hline Urine routine & 10-12 & Few RBC, $3+$ albumin & No RBC, \\
\hline Urine protein ( $\mathrm{mg} / \mathrm{m}^{2} /$ hour $)$ & $\begin{array}{l}\text { RBC, } 3+ \\
\text { albumin } \\
\text { - }\end{array}$ & $82 \mathrm{mg} / \mathrm{m}^{2} / \mathrm{hr}$ & $\begin{array}{l}3+ \\
\text { albumin } \\
40 \mathrm{mg} / \\
\mathrm{m}^{2} / \mathrm{hr}\end{array}$ \\
\hline C3 (Normal 50-150 mg/dL) & $23.4 \mathrm{mg} /$ & $129 \mathrm{mg} / \mathrm{dL}$ & $34 \mathrm{mg} / \mathrm{dl}$ \\
\hline C4 (Normal $20-50 \mathrm{mg} / \mathrm{dL}$ ) & $\begin{array}{c}\mathrm{dl} \\
2.98 \mathrm{mg} / \\
\mathrm{dl}\end{array}$ & $37 \mathrm{mg} / \mathrm{dL}$ & $10 \mathrm{mg} / \mathrm{dl}$ \\
\hline ANA & $\begin{array}{c}4+ \\
\text { diffuse }\end{array}$ & $3+$ & $\begin{array}{c}3+ \\
\text { diffuse }\end{array}$ \\
\hline Anti dsDNA (N: <60 IU/mL) & 890 & $<60$ & 123 \\
\hline Antiphospholipid antibodies: a) & Negative & Negative & Positive \\
\hline $\begin{array}{l}\text { Lupus anticoagulant b) } \\
\text { Anticardiolipin antibody (IgG and } \\
\text { IgM) c) Anti B2 Glycoprotein -1 } \\
\text { antibody (IgG \& IgM) }\end{array}$ & $\begin{array}{l}\text { Negative } \\
\text { Negative }\end{array}$ & Negative Negative & $\begin{array}{l}\text { Negative } \\
\text { negative }\end{array}$ \\
\hline Skin biopsy & Not done & $\begin{array}{l}\text { Positivity of lupus band test with } \\
\text { high positive } \lg G \text {, IgA, IgM and } \\
\text { C3 in dermal vessels }\end{array}$ & $\begin{array}{l}\text { Lupus } \\
\text { band test } \\
\text {-positive }\end{array}$ \\
\hline Renal biopsy & $\begin{array}{l}\text { Class } 3 \\
\text { lupus } \\
\text { nephritis }\end{array}$ & $\begin{array}{l}\lg G, \lg A, \lg M \text { positivity in the } \\
\text { mesangium as well as capillary } \\
\text { loops and } C 3 \text { in small sized } \\
\text { blood vessels }\end{array}$ & $\begin{array}{l}\text { Class } 4 \\
\text { lupus } \\
\text { nephritis }\end{array}$ \\
\hline Serum amylase $(<100 \mathrm{U} / \mathrm{L})$ & $238 \mathrm{U} / \mathrm{L}$ & $400 \mathrm{U} / \mathrm{L}$ & $290 \mathrm{U} / \mathrm{L}$ \\
\hline Serum lipase $(<60 \mathrm{U} / \mathrm{L})$ & $231 \mathrm{U} / \mathrm{L}$ & Not done & Not done \\
\hline
\end{tabular}

Conclusion: Pancreatitis can at times, be the presentation of childhood lupus and requires prompt and aggressive management.

Disclosure of Interests: None declared

DOI: 10.1136/annrheumdis-2019-eular.7507

\section{AB0519 VITAMIN D CUT-OFF POINTS RELATED WITH CLINICAL FEATURES IN PATIENTSWITH ACTIVE LUPUS OR LUPUS NEPHRITIS}

Renato Guzman ${ }^{1}$, Luis Gabriel Piñeros ${ }^{2}$, Maria Camila Mejia ${ }^{2}$, Anibal Teheran ${ }^{2}$ Luis Miguel Pombo ${ }^{2}$, Vanessa Cadavid ${ }^{2}$, COMPLEXUS: GIFVTA. ${ }^{1}$ Fundación Universitaria Juan N. Corpas, Research center, Bogota, Colombia; ${ }^{1}$ Fundación Universitaria Juan N. Corpas, Research center, Bogota, Colombia

Background: Vitamin D (25OHD) has immunomodulatory properties that can play a major role in patients with active lupus or lupus nephritis. His immunomodulatory function could be influenced by demographic factors comorbidities (Charlson score), bone supplements, and other features.

Objectives: We explored the association between the best 25OHD cut-off points and specific clinical features that were present in patients with active lupus or lupus nephritis.

Methods: A retrospective descriptive research using clinical registers of patients diagnosed with systemic erythematosus lupus, attended in two rheumatology clinics was performed. A decisions tree model was used to identify the best cut-off points of $250 \mathrm{HD}[\mathrm{ng} / \mathrm{mL}]$ and clinical features associated with active lupus (SLEDAI-2k $>6$ ) or lupus nephritis.

Results: We identified 81 patients, median age 41 years, women $91.3 \%$. Active lupus and lupus nephritis were present in $69.1 \%$ and $29.6 \%$, respectively. Median 25OHD was 26.49 , without a difference at comparing with active lupus patients 24.85 , but lower in lupus nephritis patients 21.50 (p: 0.015). Lupus nephritis was absent in patients with 25OHD cutoff points $>38.8$ (alone) or $\leq 38.8$ if they were older than $>57$ years. Active lupus was always present in patients $\leq 44$ years with 1. High comorbidity or 2 . Low comorbidity plus cut-off point $25 \mathrm{OHD}>35$; in $>44$ years, both a euthyroid state and the absence of bone supplements were present in patients with active lupus.

Conclusion: Exist a strong relationship between vitamin D levels and LES activity.

\section{REFERENCES}

[1] American College of Rheumatology. Guidelines for referral and management of systemic lupus erythematosus in adults. Arthritis Rheum. 1999 Sep;42(9):1785-96

[2] Simioni J, Heimovski F, Skare T. On lupus, vitamin D and leukopenia 2016;56(3):206-211.

[3] Guzman R.A, Piñeros L.G, Theran A, Flechas J, Mejía M. AB0795 Hypovitaminosis D and Calcium Intake of Adult Population in Bogota (DICAVITD). Ann Rheum Dis 2016:75:1175-. 1176.

Acknowledgement: To Fundación Universitaria Juan N. Corpas Disclosure of Interests: None declared

DOI: 10.1136/annrheumdis-2019-eular.7662

\section{AB0520 A COMPARISON OF SHEAR WAVE ELASTOGRAPHIC FINDING OF SUBMANDIBULAR GLANDS IN PATIENTS WITH EARLY-STAGE AND NON-SJÖGREN'S SYNDROME}

Naoaki Hashimoto ${ }^{1}$, Shozo Uchiyama ${ }^{2}$, Masayasu Kitano ${ }^{3}$, Takashi Nakazawa ${ }^{4}$, Tsuyoshi Iwasaki ${ }^{5}$, Takenori Hashimoto'. ${ }^{1}$ Hashimoto Rheumatology Clinic, Osaka, Japan; ${ }^{2}$ Kansai Medical University, Temmabashi General Clinic, Osaka, Japan; ${ }^{3}$ Hyogo College of Medicine, Division of Rheumatology, Department of Internal Medicine, Nishinomiya, Japan; ${ }^{4}$ Osaka Saiseikai Nakatsu Hospital, Department of Rheumatology, Osaka, Japan; ${ }^{5}$ Hyogo University of Health Sciences, Department of Pharmacy, Kobe, Japan

Background: Salivary gland (SG) ultrasonography proved valuable fo assessing SG involvement in Sjögren's syndrome (SS) and seemed to exhibit good diagnostic properties. We have reported that the submandibular gland ultrasonography (SGUS) is a useful noninvasive and inexpensive procedure for the evaluation of the structural changes of SG in SS (ISSS 2002, EULAR 2009, EULAR 2012, EULAR 2015). However, our previously study demonstrated that although SGUS findings were useful for the diagnosis of SS with low salivary flow they were not for early stage SS with normal salivary flow (EULAR 2016). Recently, we reported that the tissue elasticity was decreased due to structural changes in the SG at the advanced stage of the disease and that the shear wave 
elastography (SWE) is useful to distinguish pathological changes of the SG between early stage with normal salivary flow and advanced stage (EULAR2018). The present study we demonstrated that the tissue elasticity was increased due to inflammation and high viscosity in the SG at the early stage of SS with normal salivary flow comparing that in non-SS patients, but was decreased due to structural changes in the SG at the advanced stage of the disease. The SWE may be a useful tool for elucidation of early stage pathological changes of the SG when salivary gland functions are not impaired in SS.

Objectives: The aim of this study was to elucidate the usefulness of SWE in early-stage SS patients.

Methods: Seventeen non-SS patients and eighty patients who fulfilled the American College of Rheumatology (ACR)/European League Against Rheumatism (EULAR) classification criteria for SS were studied. SS patients were divided into three groups according to salivary flow using gum test (VL/SS: $<5 \mathrm{~mL} / 10 \mathrm{~min}$. ( $n=33)$, L/SS: $5-10 \mathrm{~mL} / 10 \mathrm{~min} . \quad(n=32)$ and N/SS: $\geqq 10 \mathrm{~mL} / 10 \mathrm{~min}$. $(n=15)$ ). All patients were examined SGUS by a single investigator who was blinded to device (TUS-A300; Canon Medical Systems, Tokyo, Japan) with a linear transducer $(7.5-10 \mathrm{MHz})$. The examination consisted of conventional B-mode US (US staging score), pulsed wave Doppler US (PD grading score) and SWE with quantitative assessment. US staging scores were assessed by glandular size, inhomogeneity and contrast of diagastric muscle (stage 0 to 3 ). PD grading scores were graded by pulsed wave pattern in pulsed wave Doppler US at the internal SG facial arteries (grade 0 to 2). With the region-of-interest (ROI) placed over the stiffest areas of the lesion on SWE, the quantitative mean of the elasticity values were measured by shear wave velocity (Vs: $\mathrm{m} / \mathrm{s}$ ) and elasticity (E: $\mathrm{kPa})$ for each lesion.

Results: The Vs and $\mathrm{E}$ values were correlated with US staging score $(r=-0.56, \quad p<0.001, \quad r=-0.58, \quad p<0.001)$ and $P D$ grading score $(r=-0.51$, $\mathrm{p}<0.001, \mathrm{r}=-0.52, \mathrm{p}<0.001)$ in all patients. There was no significant difference between non-SS and N/SS in early-stage SS by US staging score $(0.77 \pm 0.90$ vs $1.20 \pm 0.86)$ and $P D$ grading score $(0.18 \pm .053$ vs $0.53 \pm 0.19)$. However, the values of $V s$ and $E$ were highest in N/SS as compared with all groups, and significantly higher in N/SS than in non-SS (Vs: 1.73 \pm 0.18 vs $2.03 \pm 0.28 \mathrm{~m} / \mathrm{s}, \mathrm{p}<0.01, \mathrm{E}: 9.38 \pm 1.17$ vs $12.73 \pm 3.63 \mathrm{kPa}, \mathrm{p}<0.01$ ). Conclusion: The present study we demonstrated that the tissue elasticity was increased due to inflammation and high viscosity in the SG at the early stage of SS with normal salivary flow comparing that in non-SS patients. The SWE may be a useful tool for the differential diagnosis between patients with non-SS and early-stage SS with normal salivary flow in contrast to conventional SGUS.

Disclosure of Interests: None declared

DOI: 10.1136/annrheumdis-2019-eular.1518

\section{AB0521 EVALUATION OF LARYNGEAL IMPAIRMENT IN PATIENTS WITH SJÖGREN'S SYNDROME}

Benedikt Hofauer, Andreas Knopf, Carmen Unterhofer, Naglaa Mansour, Lara Kirschstein, Simone Graf. Technical University Munich, Otorhinolaryngology/ Head and Neck Surgery, Klinikum rechts der Isar, Munich, Germany

Background: Hyposalivation in patients with Sjögren's Syndrome is causative for oral dryness, one of the main symptoms of this disease. So far only little attention has been paid to a possible impairment of laryngeal functions due to the hyposalivation, even though, especially in younger and working patients, signs of laryngeal involvement often have an impact on the patient's quality of life.

Objectives: The objective of this study is to evaluate the laryngeal impairment in patients with Sjögren's Syndrome.

Methods: Patients with Sjögren's Syndrome diagnosed according to the AECG classification criteria were included in this study. Salivary function was evaluated by the measurement of the unstimulated salivary flow (USF). The laryngeal function was evaluated according to the European Laryngological Society protocol ${ }^{1}$, which includes five different items: perception (roughness, breathiness, hoarseness), videostroboscopy, acoustics (jitter, dysphonia severity index, DSI), aerodynamics and subjective rating by the patient (voice handicap index, $\mathrm{VHI}$ ).

Results: Eighteen patients (15 female, mean age 63 years) were included in the examination. Mean USF was $0.6 \mathrm{ml} / 5 \mathrm{~min}( \pm 0.5)$. The auditory-perceptual assessment resulted in slight and moderate deviance in 14 and 2 patients for roughness of the voice, in slight and moderate deviance in 12 and 3 patients for breathiness and in slight, moderate and severe deviance in 14, 3 and 1 patient for hoarseness. Evaluation of acoustics resulted in abnormal values in 12 patients (67\%). DSI revealed mild dysphonia in 7, moderate dysphonia in 6 and severe dysphonia in 1 patient. Evaluation of aerodynamics was abnormal in 12 (maximum phonation time) and 11 (phonation quotient) patients. Analysis of the VHI resulted in grade 0 in 5 patients (almost certainly not noticeable suffering), grade 1 in 8 patients (more likely unnoticeable than conspicuous suffering), grade 2 in 3 patients (more probably noticeable than not) and grad 3 in 2 patients (certainly noticeable suffering).

Conclusion: The evaluation of various laryngeal functions in patients with Sjögren's Syndrome unfolded an impairment of different aspects. Questions on laryngeal involvement should be implemented in the anamnesis of these patients and the application of screening methods should be further investigated.

\section{REFERENCES}

[1] Dejonckers $\mathrm{PH}$, et al. A basic protocol for functional assessment of voice pathology, especially for investigating the efficacy of (phonosurgical) treatment and evaluating new assessment techniques. Guideline elaborated by the Committee on Phoniatrics of the European Laryngological Society (ELS). Eur Arch Otorhinolaryngol 2001.

Disclosure of Interests: Benedikt Hofauer Consultant for: Consultant for Galvani Bioelectronics for the area of sleep disorders., Andreas Knopf: None declared, Carmen Unterhofer: None declared, Naglaa Mansour: None declared, Lara Kirschstein: None declared, Simone Graf: None declared

DOI: 10.1136/annrheumdis-2019-eular.5558

\section{AB0522 1 SEASONAL DIFFERENCE IN CEREBRAL STROKE FREQUENCY IN PATIENTS WITH SYSTEMIC LUPUS ERYTHEMATOSUS}

Wen-Nan Huang ${ }^{1}$, Yi-Ming Chen ${ }^{1,2}$, Yi-Hsing Chen ${ }^{1}$, Wei-Ting Hung ${ }^{1}$, YuWan Liao ${ }^{1} .{ }^{1}$ Taichung Veterans General Hospital, Division of Allergy, Immunology and Rheumatology, Taichung, Taiwan, Republic of China; ${ }^{2}$ Taichung Veterans General Hospital, Department of Medical Research, Taichung, Taiwan, Republic of China

Background: The incidence of stroke is well-known as increased in winter season in general population, but seasonal difference in the systemic lupus erythematosus remain unclearified.

Objectives: The aim of study was to assess seasonal difference in cerebral stroke among patients with systemic lupus erythematosus.

Methods: We conducted a retrospective case-control study analyzing hospital database of a tertiary referral center in Taiwan. From January, 2002 to December 2017, subjects with systemic lupus erythematosus and cerebral stroke were enrolled. To examine the seasonal incidence of cerebral stroke, we analyzed data from the date of CT scan/MRI/MRA. The onset time was divided into four seasons (according Local season classification): spring (March, April, May), summer (June, July, August), autumn (September, October, November), and winter (December, January, February).

Results: In total, 4313 systemic lupus erythematosus patients were identified, 261 patients with cerebral stroke. Age of patients with cerebral stroke ranged 27 between 77 years, a mean age was 55-62 years Female was predominant. Disease duration was longer in ischemia stroke group (4.8 years). According CT or MRI results, divided 4 types (Ischemia stroke (IS), ICH, SAH, SDH), 83\% (150/180) cerebral stroke was ischemia stroke. $8.3 \% \mathrm{ICH}, 5.5 \% \mathrm{SAH}, 2.8 \% \mathrm{SDH}$ found respectively. We noted a higher incidence of SLE with ischemia stoke in summer season $(38.7 \%)$, the lowest incidence of ischemia stroke in winter season $(18.7 \%)$. Patient with $\mathrm{ICH}$ has similar trend. But not found in $\mathrm{SAH}$ and $\mathrm{SDH}$

Conclusion: Incidence of systemic lupus erythematous with cerebral stroke varied in different pattern. The present findings suggested an increase in the incidence of Ischemia stroke and $\mathrm{ICH}$ in summer season. Awareness of risk factors (esp. antiphsopholipid antibodies) was essential to prevent cerebral stroke in SLE.

Table Seasonal difference in different types of cerebral stroke

\begin{tabular}{lcccc}
\hline & $\mathrm{IS}(\mathrm{n}=150)$ & $\mathrm{ICH}(\mathrm{n}=15)$ & $\mathrm{SAH}(\mathrm{n}=10)$ & $\mathrm{SHA}(\mathrm{n}=5)$ \\
\hline Age & 60 & 59.0 & 60.5 & 55.0 \\
& $(46.8-75.0)$ & $(35.0-68.0)$ & $(43.3-77.3)$ & $(27.0-71.0)$ \\
Gender\% (F/M) & $73.3 / 26.7$ & $66.7 / 33.3$ & $90.0 / 10.0$ & $60.0 / 40.0$ \\
Disease duration & $4.8(0.3-8.7)$ & $2.5(0.0-5.5)$ & $3.9(0.0-11.6)$ & $0.0(0.0-11.5)$ \\
Season & & & & \\
Spring (3-5) & $21.3 \%$ & $26.7 \%$ & $20.0 \%$ & $60.0 \%$ \\
Summer (6-8) & $38.7 \%$ & $53.3 \%$ & $20.0 \%$ & $20 \%$ \\
Autumn (9-11) & $21.3 \%$ & $6.7 \%$ & $30.0 \%$ & $20 \%$ \\
Winter (12-2) & $18.7 \%$ & $13.3 \%$ & $30.0 \%$ & $0 \%$ \\
\hline
\end{tabular}

